\title{
Hiperestentsioa: kontinenteen apurketa ulertzeko eredu berri bat
}

\section{(Hyperextension: a new model to comprehend continental breakup)}

\author{
Martin Ladron de Guevara*1, Arantxa Bodego ${ }^{1}$, Eneko Iriarte ${ }^{2}$ \\ ${ }^{1}$ Geologia Saila. Zientzia eta Teknologia Fakultatea (UPV/EHU) \\ ${ }^{2}$ Laboratorio de Evolución Humana, Dpto. de Historia, Geografía y Comunicación. \\ Universidad de Burgos
}

\begin{abstract}
LABURPENA: Kontinenteen apurketa luzaroan ikertu den prozesu geologikoa da. Rifting deritzon prozesu horrek milioika urte irauten ditu, eta kontinente-ertzetan, mendikateetan eta bestelako ingurune geologikoetan topatzen dira fenomeno tektoniko horren aztarnak. Plaka tektonikoen banaketaren interpretazioa, ordea, eboluzionatuz doa ikertzaileen ulermenaren eta aurrerapen teknologikoen arabera. Hiperestentsioaren ideia da interpretazio horren azken berrikuntza. Ideia hori litosfera kontinentalaren deformazio polifasikoan barneratzen da, litosferaren muturreko luzapenean oinarrituz, hain zuzen. Ertz egonkorretan eta gerriko orogenikoetan identifikaturiko egitura geologiko eta eremu estruktural bereizgarriek ahalbidetzen dute fenomeno horren bilakaeraren nolakotasuna definitzea. Magman txiroak bezala ezagutzen diren ertz egonkorretako eremu horiek dira hurbileko domeinua, necking domeinua, urruneko domeinua edo hiperluzatua eta kanpoko domeinua. Domeinu horietako bakoitza riftingaren deformazio faseekin lotzen da; fase horiek litosfera kontinentalaren luzapena, mehetzea, mantuaren azaleratzea eta lurrazal ozeanikoaren zabaltzea dira. Esan bezala, iraganean hiperluzatutako arroetan ari da garatzen ikerketa, eta hipotesi horren bitartez ulertzen hasia da, honezkero, Euskokantauriar arroa (EKA) barneratzen duen Iberia eta Eurasia arteko Mesozoikoko rift-sistemaren garapena. Urteetan arroan bildutako datuek, behintzat, horretara bultzatzen dute. Pirinioen mendebaldean deskribaturiko mantuaren azaleratzeak eta arroan deskribaturiko hamaika prozesuk indartu dute Kretazeoko riftingean hiperestentsioak izan zezakeen garrantzia; azken horrek, gainera, garai hartako EKAren eboluzio geologikoaren paradigma argitu dezake.
\end{abstract}

HITZ GAKOAK: rifting, hiperestentsio, plaken tektonika, Euskokantauriar arro.

\begin{abstract}
Continental breakup is a geological process which has been deeply learnt. The keys of that tectonic phenomena, the so-called rifting process that lasts millions of years, can be found worldwide within rifted margins, mountain chains and other geological settings. However, the interpretation of tectonic plate rupture evolves while researcher's comprehension and technology advance. Hyperextension is the last update within that interpretation. This revolutionary idea involves the extreme polyphasic extensional deformation of the continental lithosphere. Characteristic geological structures and structural domains identified within passive margins and orogenic belts, allow to define the evolution of this phenomena. Domains such as the proximal domain, necking domain, distal or hyperextended domain and outer domain are distinguishing features within magma poor rifted margins. These domains are linked to specific deformation phases during rifting, being stretching and thinning of continental lithosphere, mantle exhumation and oceanic crust spreading part of these process. As said, research is being carried out in hyperextended basins, and the evolution of the Iberia-Eurasia Mesozoic rift system, which involves the Basque-Cantabrian Basin (BCB), is already being understood within that hypothesis. Data collected over years in the BCB, at least, suggest that. Mantle exhumation described in the western Pyrenees and several processes linked to that within the $B C B$, reinforces the significance that hyperextension could have occurred during the Cretaceous rifting, shedding light to the paradigm concerning the evolution of the $B C B$.
\end{abstract}

KEYWORDS: rifting, hyperextension, plate tectonics, Basque-Cantabrian Basin.

\footnotetext{
* Harremanetan jartzeko / Corresponding author: Martin Ladron de Guevara. Geologia Saila, Zientzia eta Teknologia Fakultatea (UPV/EHU). - martin.ladrondeguevara@ehu.eus - https://orcid.org/0000-0001-7879-0709
}

Nola aipatu / How to cite: Ladron de Guevara, Martin; Bodego, Arantxa; Iriarte, Eneko (2021). «Hipertentsioa: kontinenteen apurketa ulertzeko eredu berri bat». Ekaia, 40, 2021, 223-245. (https://doi.org/10.1387/ekaia.21872).

Jasotze-data: 2020, ekainak 30; Onartze-data: 2021, urtarrilak 27.

ISSN 0214-9753 - eISSN 2444-3581 / (c) 2021 UPV/EHU

(7) $\odot$ Lan hau Creative Commons Aitortu-EzKomertziala-LanEratorririkGabe 4.0 Nazioartekoa 


\section{SARRERA}

XX. mendearen hasieran Alfred Wegener meteorologo eta geofisikari alemanak lehendabizikoz iradoki zuen kontinenteen jitoa izan zen 50 urte beranduago garatuko zen plaken tektonikaren teoriaren aurrekaria. Egun, komunitate zientifikoak aho batez onartzen du teoria hori, Lurreko prozesu natural asko uler baitaitezke bertan oinarriturik. Teoria horren gainean eraiki da gaur egun gizarteak duen jakinduria geologikoaren zati handi bat, eta seguruenik horrela izaten jarraituko du etorkizunean ere. Plaken tektonikaren barneko prozesu primario horietako bat da riftinga: indar dibergenteen eraginpean litosfera kontinentala luzatu, mehetu eta zatikatu egiten da, plaken arteko muga berriak sortuz. Munduko hidrokarburo-erreserben zati handi bat garapen-maila ezberdineko rift-sistemei lotuta dago. Eremu geologiko berezi horiek gordetzen duten potentzial ekonomikoa handia da, eta, horregatik, xeheki aztertu dira hidrokarburo-enpresa esploratzaileen aldetik urteetan zehar. Dena dela, industria horri lotuta, 70eko hamarkadan sortutako kontinenteen banaketari buruzko eredu iraultzaile honek eraldaketa nabarmenak izan ditu. Aurrerakuntza teknologikoen poderioz, datu berri asko isuri dira mahai gainera. Hasierako ideiatik abiaturik, riftinga ulertzeko ereduek hamaika aldaketa izan dituzte: kontzeptu eta hipotesi berriak txertatu dira, eta pixkanaka ulertu dira hasieran ulergaitzak ziren fenomenoak.

Ideia horietako bat da azken hamarkadotan hainbat ikertzailek eskuartean darabilten hiperestentsioaren hipotesia [1-3]. Ideia horrek datu geofisiko, geokimiko eta sedimentologiko berriak txertatu ditu urteetan zehar garatzen joan den rifting-ereduaren urruneko gune eta gutxi ezagunean [4]; ondorioz, behaketa berriak antzeman eta kontzeptu berriak sortu dira [5-8]. Rifting-prozesuaren baitan gertatzen den lurrazal kontinentalaren muturreko luzapena da hiperestentsioa. Aurrez luzatutako eta meheturiko lurrazal kontinentalak luzatzen jarraitzen du fase honetan, detachment faila-sistema baten bitartez. Subhorizontalak izatera hel daitezkeen angelu txikiko faila normal horiek lurrazal kontinental hauskor osoa zeharkatzen dute, eta mantuko arrokak itsas hondoan azaleratzera iristen dira [9, 10]. Esfortzu estentsionalek aurrera jarraituz gero, kontinente-litosferaren apurketa gerta daiteke, eta lurrazal ozeaniko berria eratuko duen proto-gandor ozeaniko bat sortu.

Gauzak horrela, hiperestentsioa eta horri lotutako fenomenoak munduko hamaika tokitan ari dira aztertzen. Esaterako, ideia hori funtsezko bilakatu da Ozeano Atlantikoaren irekiera nolakoa izan zen ulertzeko. Atlantikoko zenbait ertz egonkor konjugatuen kasua da; Iberia-Ternua, Angola-Brasil edota Norvegia-Groenlandia, esaterako [7, 11, 12]. Australia-Antartika sisteman edota Txina hego-ekialdeko itsasokoan ere antzeman dira hiperestentsioaren zantzuak [13, 14]; iraganean rift-arroak izan 
ziren, baina inbertsio tektonikoaren bitartez gaur egun gerriko orogenikoen parte diren Pirinioak eta Alpeak ere eredu honen bidez hasi dira interpretatzen [1, 15-18].

Eta nola ez, iraultza horrek badu zeresana Euskokantauriar arroan (EKA) ere. Arro horretako Mesozoiko garaiko geologia xehetasun handiz aztertu da urteetan zehar. Aurkikuntza horiek barneratzen dituen eboluzio geologikoaren historia eraikitzea, ordea, ez da inoiz zeregin makala izan [19], eta, antzemandako Kretazeoko estentsioaren fenomeno eta faktore garaikide guztiak barneratzen dituen teoria ez da aho batez onartu, oraindik. Jada, bada hiperestentsioari tokia egin dion autorerik ere [20-24], eta, agian, ideia horrek azal ditzake EKAn erregistratutako garai horretako prozesu eta fenomeno geologikoak.

\section{LITOSFERA KONTINENTALA, ERREOLOGIAREN IKUSPUNTUTIK}

Riftinga ulertzeko litosfera kontinentalaren egitura ezagutu behar da lehenik (1a. irudia). Litosferaren egituraketak eta horrek deformazioaren menpean emandako erantzunak berebiziko garrantzia dute rift-arro baten sorreran eta bilakaeran. Historikoki hainbat eredu plazaratu dira litosferak duen portaera erreologikoa deskribatzeko, baina, gaur egun, jelly sandwich gisa ezagutzen dena da, oro har, eredu onartuena [25-27] (1b. irudia). Eredu horretan, zurrunak eta hauskorrak diren bi eremu bereizten dira, eta plastikoagoak eta moldakorragoak diren beste bi eremurekin txandakatzen. Eremu zurrun horiek dira kontinente-lurrazalaren goiko aldea eta mantu litosferikoaren goiko zatia; plastikoagoak dira, berriz, kontinente-lurrazalaren beheko aldea eta mantu litosferikoaren beheko zatia. Ikusi denez, deformazioaren aurrean, portaera mekaniko desberdinak bereizten dira unitate bakoitzak dituen propietate fisiko, kimiko eta mineralogikoengatik. Erreologiaz gain, kontuan hartu behar da litosfera kontinentalaren lodiera eta izaera heterogeneoa ere. Kontinentelitosferaren lodiera oso aldakorra da; 100 eta $350 \mathrm{~km}$ bitartekoa dela balioesten da. Eta, era berean, kontinente-lurrazalarena ere 20 eta $70 \mathrm{~km}$ bitartekoa izan daiteke. Hori guztia kontuan izanda, esan daiteke litosfera kontinentala barneratzen duten plaka guztiek ez dutela berdin jokatzen esfortzuen menpean, eta horrek zeharo eragin dezake kontinentelitosferaren apurketan. 


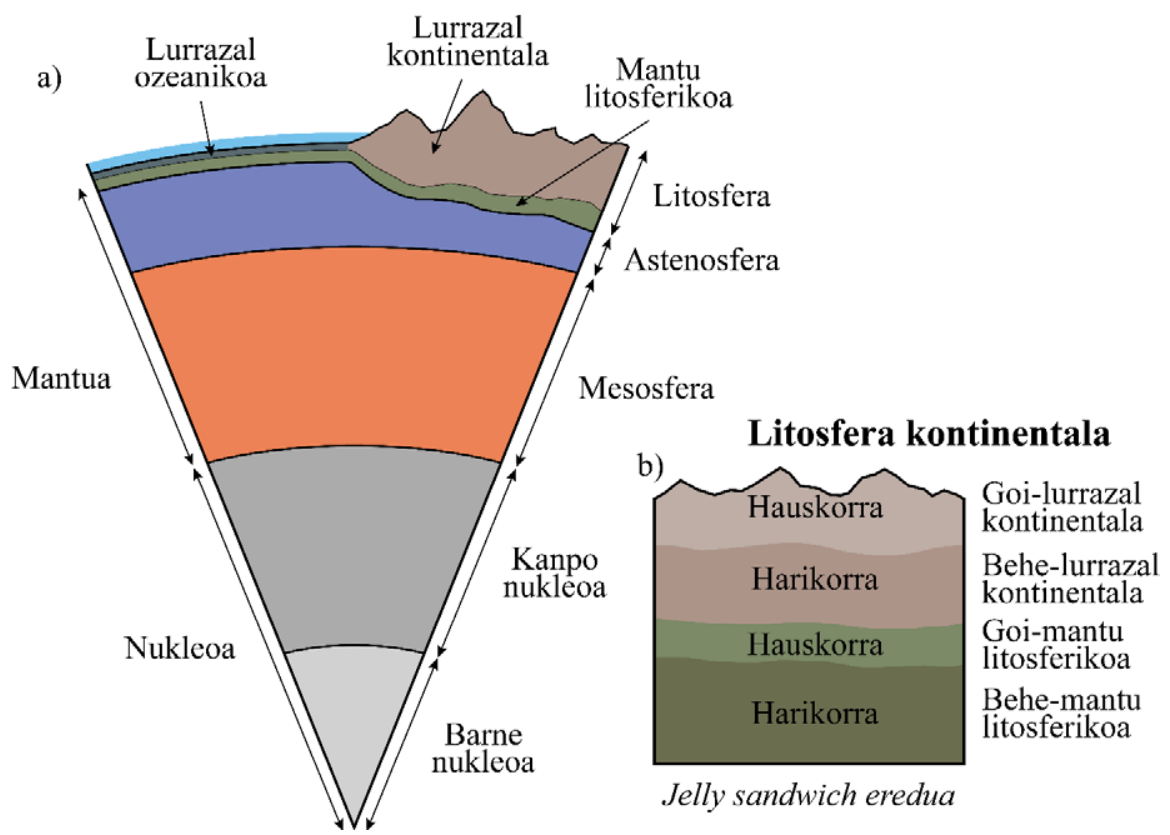

1. irudia. a) Lurraren egituraren irudi eskematikoa (eskala gabeko irudia), konposizioan (ezkerrean) eta erreologian (eskuinean) oinarrituta; b) litosfera kontinentalaren banaketa, erreologiaren ikuspuntutik, jelly sandwich ereduan oinarritua.

\section{RIFTINGA ETA HIPERESTENTSIOA}

\subsection{Rifting-prozesuaren sorrera}

Riftingak litosfera kontinentalaren luzatze, mehetze eta azkeneko apurketa bitarteko prozesu guztiak barneratzen ditu. Riftinga litosfera kontinentalaren eskualde-eskalako esfortzuekiko erantzun pasiboa da, eta esfortzu horien jatorria ezberdina izan daiteke. Izan ere, bereizi egiten dira sorrera aktiboa edo termikoki aktibatutakoa eta sorrera pasiboa (2. irudia).

Rifting aktiboan, mantuan zehar gora doan luma gorakorrak litosfera zurrunaren kontra jotzean eragiten ditu estentsio-indarrak. Dinamika horrek mantu astenosferikoaren gorakada eta litosferaren konkortzea eragiten ditu, eta, ondoren, zartatu egiten da. Rifting pasiboan, aldiz, plakek eragindako urruneko indar orokorrek (far field forces) eragiten dute litosfera kontinentalean estentsioa; lehendabizi lurrazala zartatzen dute, eta, ondoren, mantu astenosferikoaren gorakada eragin. Horrela, rifting aktiboan prozesu bolkanikoak hasiera-hasieratik gertatzen dira, azaleko arro sedimentarioa garatu aurretik; rifting pasiboan, berriz, prozesu bolkanikoak azaleko arro 
sedimentarioa sortu ondoren gertatzen dira. Hala eta guztiz ere, bi eredu horiek muturreko eredu idealak dira, eta, seguruenik, bitarteko prozesu guztiak ere gerta daitezke. Gainera, oso garrantzitsua da kontuan izatea iraganeko egitura geologiko nagusiek etorkizuneko prozesuak baldintzatu ditzaketela [28], oso ohikoa baita deformazioa gune konkretu horietan kontzentratzea. Gune horiek, askotan, ahultasun-eremu gisa jokatzen dute; deformatzerako garaian, gainera, errazagoa da aurretik ahuldutako eremu batetik hastea, propietate fisikoen aldetik homogeneoagoa den beste batetik hastea baino. Horretaz gain, denbora da beste faktore garrantzitsuenetako bat. Izan ere, denboran zeharreko esfortzuen irauteak zeharo baldintzatzen du eskualde-eskalako deformazioaren bilakaera oro.

(a) Rifting aktiboa

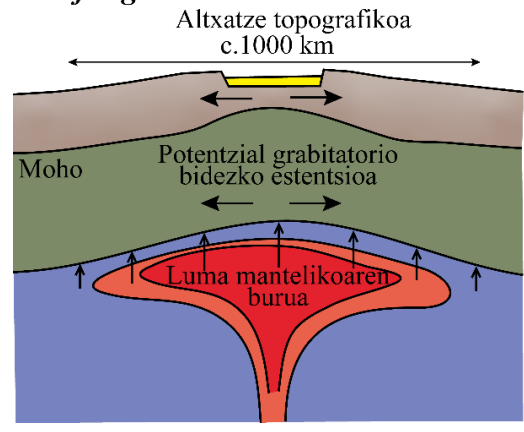

(b) Rifting pasiboa

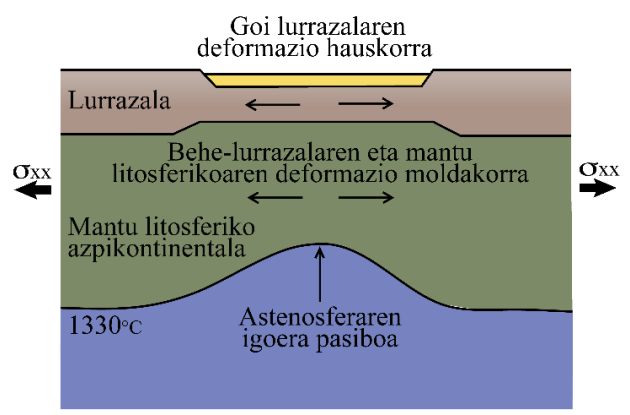

2. irudia. a) Rifting aktiboa eta b) rifting pasiboa. [25]etik moldatua.

\subsection{Magman txiroak eta aberatsak diren kontinente-ertzak}

Plaken tektonikaren ikuspuntutik aktiboak ez diren kontinente-lurrazalaren eta lurrazal ozeanikoaren trantsizioguneak dira ertz egonkorrak. Kontinente-ozeano trantsizioak ehunka kilometro luze izan ditzake, eta bertan zenbait eremu edo domeinu bereizten dira (3. irudia): hurbileko domeinua, necking domeinua, urruneko domeinua eta kanpoko domeinua. Oro har, ertzak bi multzotan sailkatu izan dira azken 30 urteetan, kausa genetikoen eta zenbait faktore bereizgarriren arabera [3, 29]: magman txiroak eta magman aberatsak diren ertzak.

Magman aberatsak diren ertzek edo ertz bolkanikoek, izenak dioen bezalaxe, magma-hornidura erlatibo handia izaten dute kontinenteen apurketa gertatzen denean. SDR (Seaward dipping reflectors) deritzen bolumen handiko pilaketa magmatikoak dira ertz mota horren ezaugarri nagusia (3. irudia). Gainera, apurketa hori airepean gertatzen da. Horretaz gain, necking domeinua erlatiboki estua izan ohi da, eta Moho etenunearen sismika bidezko identifikazioa nahiko erraza da sistema osoan zehar. Horrek guztiak, 
beste faktoreen artean, ertz horien estentsioa erlatiboki azkarra dela iradokitzen du ( 25-30 mm/yr) [30]. Normalean, rifting aktiboa izan ohi da mota horretako ertzen jatorria [31].

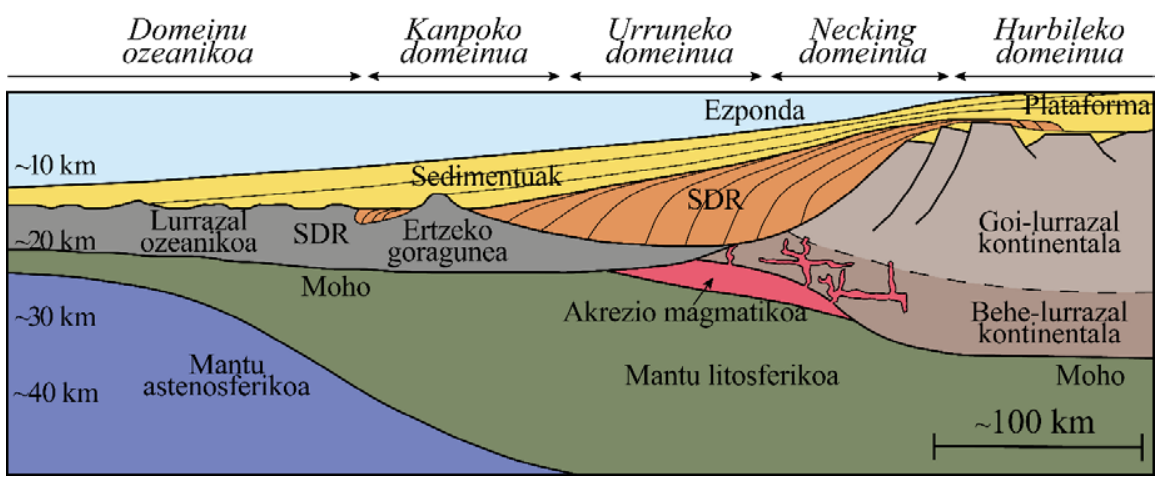

3. irudia. Ertz egonkor bolkaniko baten zehar-ebaki eskematikoa. [30] lanetik hartua eta moldatua.

Magman txiroak diren edota hiperluzatutako ertzek beste ezaugarri batzuk erakusten dituzte (4. irudia). Aurrekoek ez bezala, ertz horiek jarduera magmatiko erlatiboki txikia erakusten dute, nahiz eta guztiz antzuak ere ez diren (arroka magmatikoen bolumena ertz bolkanikoen jardueraren \% 10 ingurukoa dela balioesten da). Apurketari dagokionez, itsaspean izaten da. Izan ere, necking domeinua eta urruneko domeinua askoz zabalagoak dira. Bestalde, mantu serpentinizatuaren aztarnak ere mota horretako ertzetan topatzen dira, eta mantua azaleratzen den eremuetan nekezagoa edo ezinezkoa da Moho etengunea identifikatzea, higaturik egon daitekeelako. Gauzak horrela, hiperluzaturiko ertz horien eboluzioa askoz ere motelagoa dela proposatu da $(\sim 10 \mathrm{~mm} / \mathrm{yr})$ [32]. Ertz horien jatorria, bolkanikoena ez bezala, rifting pasiboan dagoela uste da [33].

Rift-ertz batzuk besteak baino azkarragoak izatearen arrazoia parte hartzen duten eragileen erlazioari lotzen zaio, gaur egun. Afrikako riftean ikusi denez, kontinenteen apurketa azkarraren jatorria plakek eragindako urruneko indar orokorren eta termikoki aktibaturiko riften indarren aldiberekotasuna da (Itsaso Gorria, esaterako). Aldiz, mantuko luma gorakorren kokapenetik geroz eta urrunago (Afrika ekialdeko riftaren hegoaldean), far field indarrek soilik eragiten dute, eta, ondorioz, motelagoa da kontinenteen banatzea [34]. Gainera, magmaren horniduraren desberdintasuna ere indar eragileen jokaera horrek azaldu dezake. Hala ere, argi dago riften zabaltzea eta zabaltze horren mugak litosfera-eskalako prozesu eta parametroen menpe daudela [29]. 


\subsection{Hiperluzaturiko kontinente-ertzen arkitektura}

Ozeano Atlantikoaren bi ertzetan eginiko zenbait behaketetan, elkarren artean konparagarriak diren elementu eta eremu estruktural bereizgarriak deskribatu dira [7]. Ertz egonkor horietan, lehenago aipatu bezala, kostaldetik hasi eta lurrazal ozeanikoa hedatzen hasten den tokiraino zenbait domeinu bereizi dira, eta bakoitzak berariazko ezaugarri estrukturalak ditu. Eremu horiek dira aurrez aipaturiko hurbileko domeinua, necking domeinua, urruneko domeinua eta kanpoko domeinua (4. irudia). Ezaugarri horiek domeinu horien arkitektura zein rift-sistemen iraganeko eboluzioa interpretatzea ahalbidetzen dute. Domeinu horien arteko mugak trantsiziozkoak dira, eta, sarri, ez da erraza ertz egonkor berean domeinu guztiak identifikatzea. Domeinu bakoitza deformazioaren prozesu eta fase ezberdinen ondorio dela uste da. Hala eta guztiz ere, prozesu desberdinen aldiberekotasuna edota gainjartzea ere gerta daiteke denboran eta espazioan zehar. Horren ondorioz, hainbat elementu gainezarririk egon daitezke, eta zailagoa da zenbait prozesu ulertzea.

\subsubsection{Hurbileko domeinua}

Hurbileko domeinua kontinenteen plataformetara mugatzen da orokorrean, nahiz eta kontinenteen barrenerago ere heda daitekeen (Eskandinaviako mendigunea Norvegiako ertzean, adibidez). Estentsioaren eragina ertaina da, luzapen-faktorea (luzapena pairatutako gorputz baten lodierak izandako aldaketa definitzen duen faktorea; adibidez, faktore hori 2koa bada, estentsioaren ondoriozko gorputzaren lodiera jatorrizkoaren erdia izango da) $2 \mathrm{z}$ azpikoa eta lurrazalaren lodiera $25-30 \mathrm{~km}$ ingurukoa. Domeinu honen egitura bereizgarriak dira lurrazalaren erdialdean, portaera hauskorraren eta moldakorraren arteko mugaren inguruan, sustraitzen diren faila normalek mugaturiko goi-lurrazaleko graben eta erdi-graben egiturak (4. eta 5a. irudiak). Failak aktiboak diren bitartean, egitura-zoko horiek sedimentuz bete ohi dira (metakin sintektonikoak), falka-itxurako gorputz sedimentarioak eratuz.

\subsubsection{Necking domeinua}

Eremu honetan, lurrazalak erakusten duen mehetzeari egiten dio erreferentzia necking terminoak (5b. irudia). Hurbileko eta urruneko domeinuen arteko trantsiziogune horretan, lurrazalaren lodiera $25-30 \mathrm{~km}$-koa izatetik $10 \mathrm{~km}$ baino txikiagoa izatera pasatzen da. Diferentzia hori behe-lurrazalaren deformazio moldakorraren ondorio da, batik bat, behe-lurrazala erabat mehetzeraino deformatua izaten baita. Lurrazalaren bat-bateko mehetze horri lotzen zaio Moho etenuneak erakusten duen geometria. Bestalde, akomodazio-espazioa nabarmen hazten da arro erdirantz [35]. Necking domeinuaren kanpoko aldean, taper break bezala ezagutzen den estugunea 
definitzen da [37]. Puntu hori lurrazala $10 \mathrm{~km}$ lodi den eta kostatik hurbilen dagoen gunea da. Lodiera horrekin, kontinente-lurrazal osoak portaera hauskorra izaten du, eta, horrela, hausturek lurrazal osoa zeharkatu eta mantuan eragiterainoko gaitasuna lortzen dute. Failek ozeanoranzko noranzkoan aurrenekoz lurrazala zeharo zeharkatzen duten gune hori coupling point gisa ezagutzen da [37] (5b. irudia).

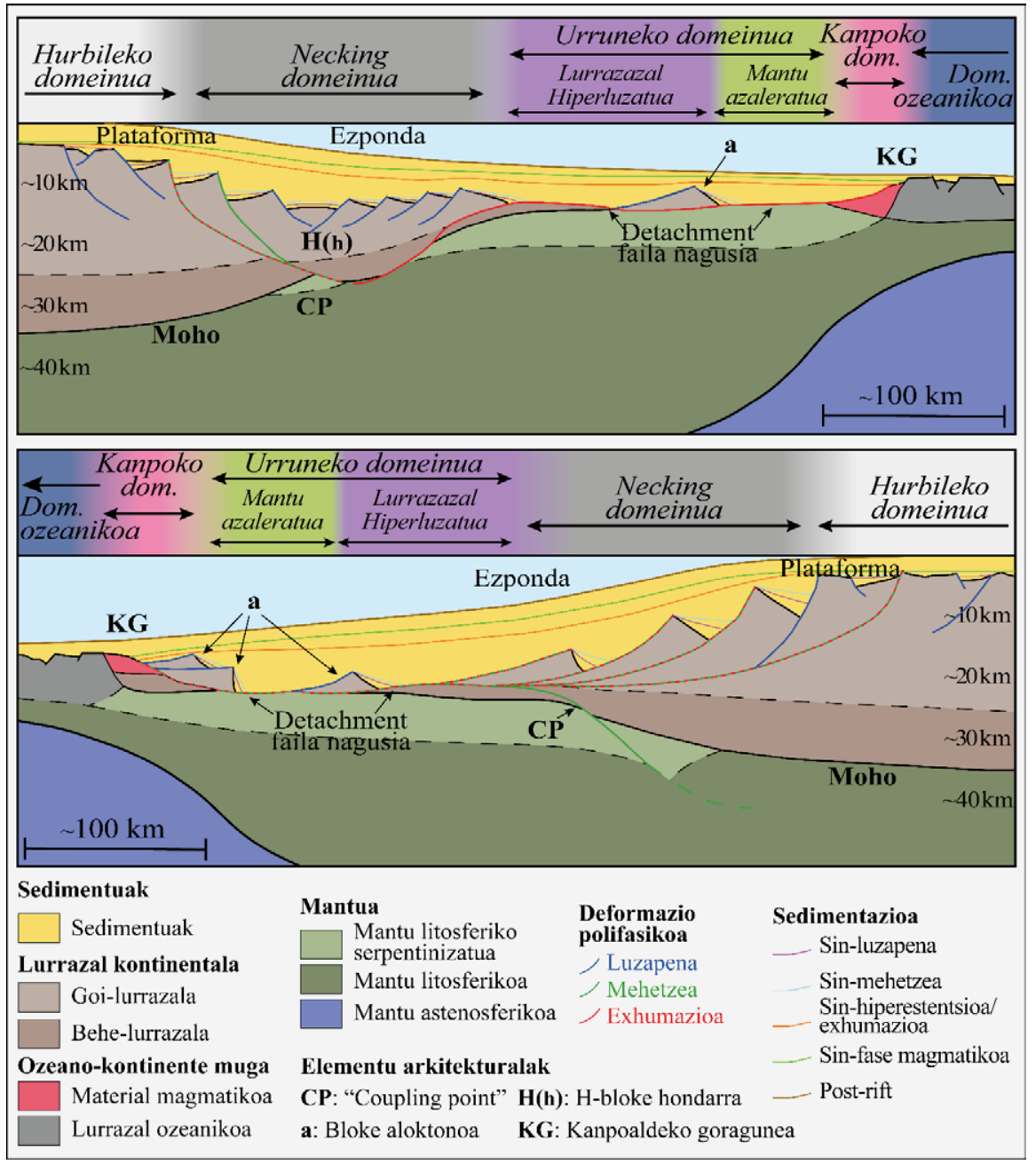

4. irudia. Hiperluzaturiko rift-ertz konjugatu baten zehar-ebaki eskematikoa. [15] lanean oinarritua eta moldatua. 
a)

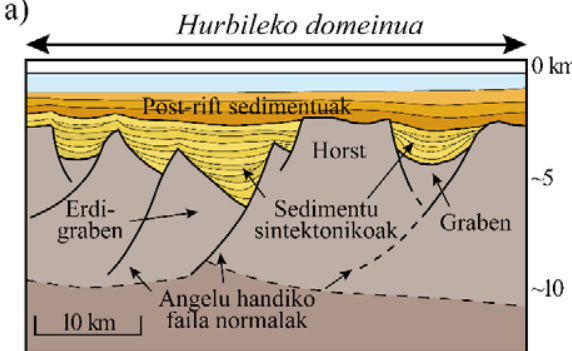

c)Domeinu Kanpoko

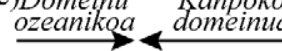

b)

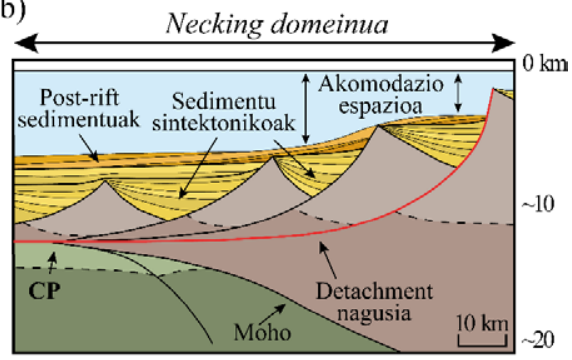

Urruneko domeinua

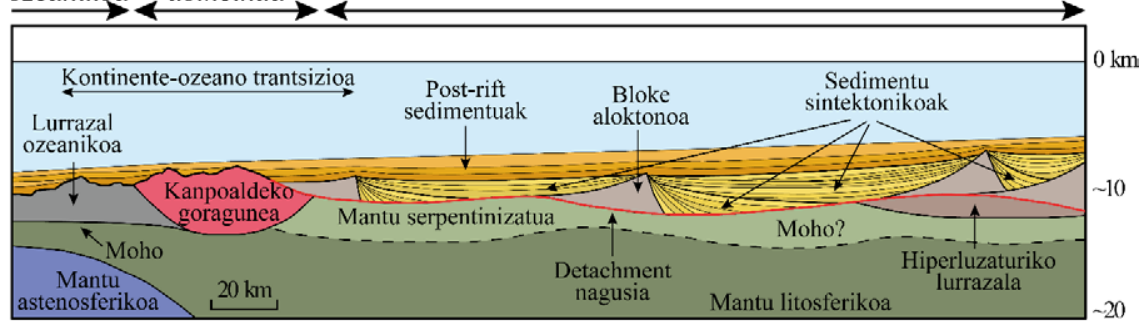

5. irudia. Hiperluzaturiko ertz egonkor baten domeinuen irudi eskematikoak: a) Hurbileko domeinua, b) Necking domeinua eta c) Urruneko eta kanpoko domeinuak. [7] lanean oinarritua eta moldatua.

\subsubsection{Urruneko domeinua}

Gutxien ezagutzen den domeinua da honako hau. Askotan, hiperluzaturiko domeinu terminoa erabiltzen da muturreraino luzatu eta mehetutako lurrazal kontinentala deskribatzeko. Domeinu horrek kontinenteeta ozeano-lurrazalaren arteko trantsizioa barneratzen du, eta eskala ezberdinetakoa izan daiteke. Lurrazal kontinentala $10 \mathrm{~km}$ baino meheagoa da, eta horren beheko muga $\mathrm{S}[38,39]$ edo $\mathrm{H}$ [40] deritzon islapen sismiko zorrotz baten bitartez definitutako detachment faila subhorizontal irregular bati dagokio (5c. irudia). Faila hori kontinente-lurrazal zatikatuaren eta neurri batean serpentinizatutako mantuaren arteko mugatzat interpretatzen da. Serpentinizazioa fluidoen zirkulazioaren bitartez mantuko arrokek garatzen duten alterazioa da; prozesu horren ondorioz, ura, askotan itsasoko uraren infiltrazioaren bitartez, mineralen kristal-egituran sartzen da, eta mineral sekundarioek (serpentina) jatorrizkoak (olibinoa, anfibola eta piroxenoa) ordezkatzen dituzte, serpentinita deituriko arroka metamorfikoak garatuz. Eremu hori goi-lurrazal zatikatuak, mantuko peridotita serpentinizatuek eta magmatismoaren ondoriozko intrusioek osatzen dutela uste da. Eremu horren ezaugarri nagusia da lurrazal plastikoaren hondarrik ez egotea [7]. Kontinentelurrazalaren geometria ere aldakorra izaten da. Ikuspegi estruktural ba- 
tean oinarrituta, hainbat gorputz edo bloke identifika daitezke. Domeinu horren eta aurrekoaren ezaugarri dira H-blokeak [2] eta bloke aloktonoak [11] (4. irudia). Bloke horien jatorria riftingaren garapenaren araberakoa da, eta bloke bakoitza prozesuaren une bati eta deformazio modu bati loturik dago. Bukatzeko, garrantzitsua da betekin sedimentarioaz hitz egitea ere. Hainbat kilometrotako lodiera izatera hel daiteke, eremu hori baita estentsio handiena jasan duen eremua. Eta hori gutxi balitz, prozesu hidrotermalek eragin handia izan dezakete sedimentu horien diagenesian, eta hainbat metalen iturri diren mineralizazioak sor ditzakete [41-44].

\subsubsection{Kanpoko domeinua}

Aurreko domeinuaren antzera, honako hau ere oso gutxi ezagutzen da. Material bolkanikoz eta sedimentuz osaturiko domeinu honek kontinente-lurrazal hiperluzatua eta hastapeneko lurrazal ozeanikoa banatzen ditu, datu sismikoen interpretazioaren arabera (5c. irudia). Magman txiroa edo aberatsa den ertz egonkorraren izaeraren arabera, terminologia desberdina erabili izan da domeinu hau deskribatzeko garaian. Ingurune bolkanikoetan, ertzeko goragune deritzo, eta apurketa kontinentalaren ezaugarri den sekuentzia magmatikoaren parte da [45]. Magman txiroak diren ertzetan, aldiz, kanpoaldeko goragune terminoa erabiltzen da [46]. Ertz horien arteko diferentzia nagusietako bat magmaren hornidura da. Magman aberatsak diren ertzetan, lurrazal kontinentalaren eta ozeanikoaren arteko ukipen zorrotzak definitzen du apurketa kontinentala. Magman txiroak diren ertzetan, aldiz, ukipen hori askoz ere lausoagoa da, eta gradualagoa da lurrazal ozeaniko-kontinentalaren trantsizioa. Domeinu horretako kontinentelurrazalaren konposizioak ezezaguna izaten jarraitzen du kasu gehienetan, antzeko egituretan ez baita nahikoa zundaketa egin. Eta hori gutxi balitz, domeinu honetaraino heda daitezke material diapirikoen pilaketa halozinetikoak, sismika bidezko irudi garbiak lortzea galarazten dutelarik (Atlantiko hegoaldean, esaterako [47]).

\subsubsection{Domeinu ozeanikoa}

Domeinu honen izaera nahiko ondo definitzen da magman txiroak edo aberatsak diren ertzen araberako parametro geofisikoen arabera, nahiz eta hemen ere urriak diren zundaketak [7]. Parametro geofisiko horiek dira uhin primarioen abiaduren homogeneotasuna, anomalia magnetikoen antolaketa eta islapen gutxi izatea. Kasuak kasu, gandor ozeanikoen bidez hedatzen den jatorri igneoko lurrazal ozeanikoaren domeinua da hau, eta nabarmen lodiagoa da magman aberatsak diren ertzetan txiroak direnetan baino. 


\subsection{Rifting-eremuetako kontinente-lurrazaleko blokeak}

Aipatu bezala, ikuspegi estruktural batetik behatuta, geometria eta jatorri ezberdineko blokeak antzeman daitezke kontinente-ertzetan. Horien deskribapen estrukturalean eta interpretazio genetikoan eginiko sailkapena ikusten da 6. irudian eta 1. taulan [11]. Bloke horien sorreraren interpretazioa behar-beharrezkoa da riftingaren bilakaera eta horrek barneratzen dituen prozesuak ulertu eta deskribatzeko. Rifting-prozesuan garatzen diren graben egituretatik, normalean, egitura guztiak ez dira arrakastatsuak izaten. Egitura batzuk bertan behera geratzen dira. Hau da, egitura horietan lurrazala ez da guztiz banatzera iristen. Sakonune horiek V formako arro gisa ezagutzen dira. Arro horiek necking domeinuen antzekoak dira, eta Iberia-Ternua ertz konjugatuko sisteman ikus daitezke, Galiziako ertzaren barnealdean, adibidez [10].

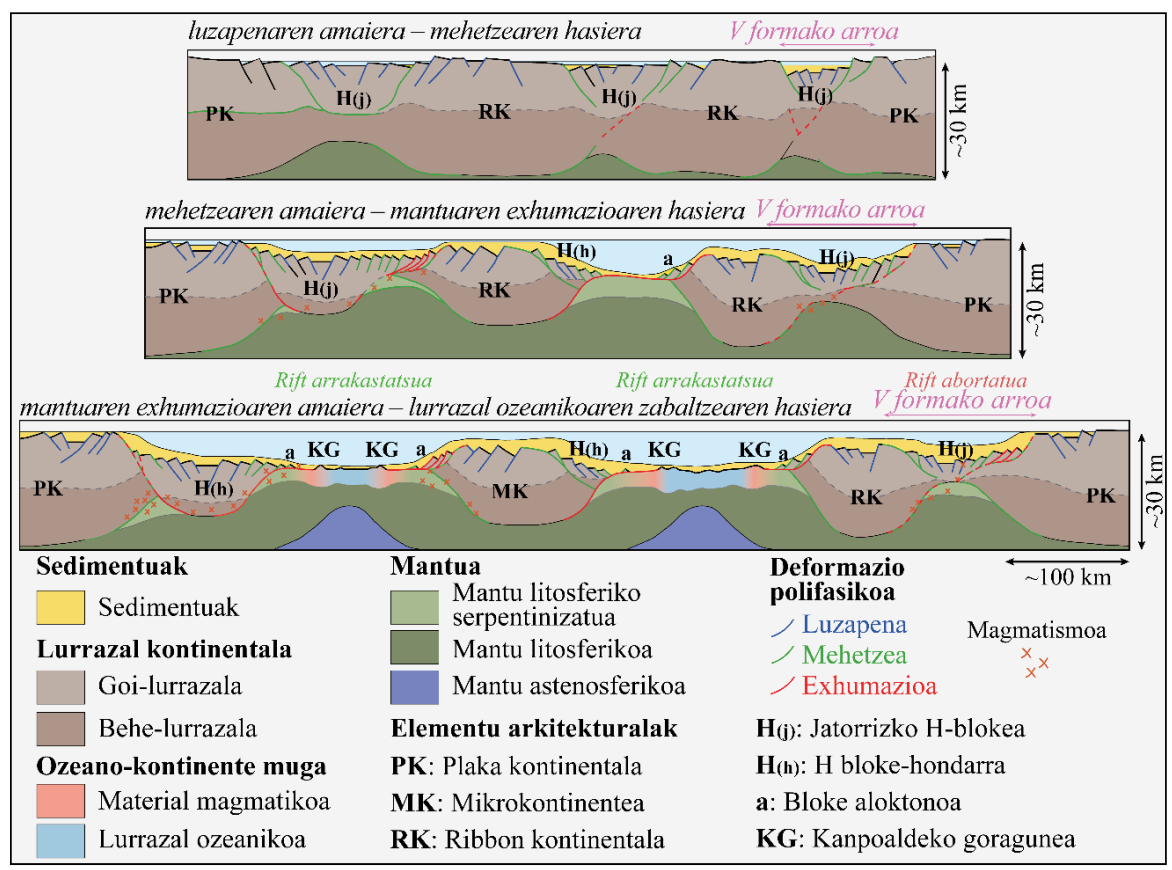

6. irudia. Rifting-prozesuan bereizten diren bloke kontinentalen eredu eskematikoa. [11] lanetik hartua eta moldatua. 
1. taula. Rifting prozesuan bereizten diren zenbait egitura kontinentalen deskribapen eta ezaugarri nagusiak. [11]lanetik hartua eta moldatua.

\begin{tabular}{|c|c|c|c|}
\hline Bloke mota & Ezaugarriak & Adibide-tipoa & $\begin{array}{l}\text { Blokeari loturiko } \\
\text { deformazio fasea }\end{array}$ \\
\hline Mirokontinentea & $\begin{array}{l}\text { Lurrazal ozeanikoz inguraturiko } \\
15 \mathrm{~km} \text { baino lodiagoko } \\
\text { lurrazal kontinentala. }\end{array}$ & Jan Mayen & $\begin{array}{l}\text { Luzapen eta mehetze faseei } \\
\text { eta batez ere luma manteliko } \\
\text { baten magmatismoari lotua }\end{array}$ \\
\hline $\begin{array}{l}\text { Ribbon } \\
\text { kontinentala }\end{array}$ & $\begin{array}{l}\text { Kontinenteari loturiko } 20 \mathrm{~km} \\
\text { baino lodiagoko lurrazal } \\
\text { kontinentala. }\end{array}$ & $\begin{array}{l}\text { Flemish Lurmuturra, } \\
\text { Galiziako Bankua, } \\
\text { Rockall Bankua }\end{array}$ & $\begin{array}{l}\text { Luzapen eta mehetze } \\
\text { faseei lotua }\end{array}$ \\
\hline H-blokea & $\begin{array}{l}\text { Kontinenteari loturiko eta } \\
\text { detachment failek mugaturiko } \\
15-20 \mathrm{~km} \text { baino lodiagoko } \\
\text { lurrazal kontinentala. }\end{array}$ & $\begin{array}{l}\text { Ternuako ertz } \\
\text { egonkorreko necking } \\
\text { domeinua, } \\
\text { Alpeetako } \\
\text { E-Briançonnais }\end{array}$ & $\begin{array}{l}\text { Mehetze eta exhumazio } \\
\text { faseei lotua }\end{array}$ \\
\hline $\begin{array}{l}\text { Bloke estentsional } \\
\text { aloktonoa }\end{array}$ & $\begin{array}{l}\text { Detachment faila gaineko } \\
5 \mathrm{~km} \text { baino lodiagoko lurrazal } \\
\text { kontinentala. }\end{array}$ & $\begin{array}{l}\text { Iberia mendebaldeko } \\
\text { ertz egonkorreko } \\
\text { domeinu hiperluzatua, } \\
\text { Alpeetako Piz Laviner }\end{array}$ & Exhumazio faseari lotua \\
\hline $\begin{array}{l}\text { Kanpoaldeko } \\
\text { goragunea }\end{array}$ & $\begin{array}{l}\text { Domeinu ozeanikoaren eta distalaren } \\
\text { arteko material bolkanikoz eta } \\
\text { sedimentuez osaturiko trantsizio } \\
\text { gunea. }\end{array}$ & $\begin{array}{l}\text { Ternuako ertz } \\
\text { egonkorreko } \\
\text { kanpoko gunea }\end{array}$ & $\begin{array}{l}\text { Kontinente-apurketari eta } \\
\text { ozeanoa zabaltzeari lotua }\end{array}$ \\
\hline
\end{tabular}

\subsection{Rifting pasiboa: luzapena, mehetzea, mantuaren exhumazioa eta hondo ozeanikoaren zabaltzea}

Rifting pasiboa eta kontinenteen apurketa lau fase jarraituetan banatzen dituzte ikerlariek, Iberiako eta Ternuako ertz egonkor konjugatuetan oinarriturik, besteak beste $[7,10]$. Fase horiek litosfera kontinentalaren luzapena, mehetzea, mantuaren exhumazioa eta lurrazal ozeaniko berriaren zabaltzea dira, hurrenez hurren. Esan daiteke litosfera kontinentalaren deformazio moduari loturiko estentsioaren migrazioaren eta estentsio horren lekutzearen ondorioa dela riftinga. Hala eta guztiz ere, fase horien sekuentzia osoa ez da beti bere osotasunean garatzen, eta, kasu batzuetan, bertan behera gera daiteke riftingaren garapena. Luzapen-faktorearen eta deformazio estentsionalaren ratioaren arabera (deformazioaren iraupena eta intentsitatea), arro ezberdinak sailkatu dira munduan zehar. Arro horiek rifting pasiboaren garapenaren une ezberdinetako argazkiak direla jo daiteke. Horien artean bereiz daitezke, esaterako, sag motako subsidentzia termaleko arroak (Ipar Ameriketako Michigan eta Illinois arroak), rift kontinentalak (Rhine grabena), abortatutako riftak (Ipar Itsasoa), ildo protoozeanikoak (Itsaso Gorria) eta ertz pasiboak (Ozeano Atlantikoko ertz egonkorrak), bilakaera horren estaien baitan [25].

\subsubsection{Luzapena}

Hurbileko domeinuan deskribaturiko angelu handiko faila normal listrikoek sorturiko horst eta graben zein erdi-graben egituren bitartez garatzen 
den subsidentzia tektonikoak bereizten du luzapen fase hau. Faila normal horiek lurrazal kontinentalaren goiko aldeko lurrazal zurrunean zein mantuaren goiko aldean eragiten duten zizaila-eremuak dira (7a. irudia). Erliebean aldaketak sortzearen ondorioz, failei loturiko arro sedimentarioak modu orokorrean eta independentean garatzen dira lurrazalean. Behe-lurrazalak duen portaera erreologikoa, ordea, plastikoagoa da, eta geruza hori argaltzearen ondorioz gertatzen da deformazioa.

\subsubsection{Mehetzea}

Estentsio-egoerak aurrera jarraitzen badu, deformazioa gune zehatzetara mugatzen hasten da, necking domeinuan antzeman daitekeen bezala. Angelu handiko faila listrikoak garatzetik, behe-lurrazaleko eta mantuko arrokak goratzen dituzten eta etzanagoak diren detachment faila sistema konjugatuak sortzen dira ( $7 \mathrm{~b}$. irudia). Faila horien gaineko blokea lehen definituriko H-blokea izaten da [11]. Era berean, faila listrikoek sedimentazioa kontrolatzen jarraitzen dute; gainera, subsidentzia tektonikoaz gain, mantuaren goratzearen ondoriozko subsidentzia termikoa ere garrantzitsua izaten da, eta, horren ondorioz, gradiente geotermikoa handitu egiten da. Fase horren beste ezaugarrietako bat da behe-lurrazala eta goi-mantua banandu egin daitezkeela zizaila-eremuen egokitzeagatik.

\subsubsection{Mantuaren exhumazioa}

Lurrazal kontinentalaren zatiketa aurrera doan heinean, detachment failek goitik behera zeharkatzen dute ahuldutako lurrazala. Lurrazalak 10-12 km-ko lodiera duenean, hauskor-moldakor muga mantuan kokatzen da, eta, ondorioz, lurrazal osoa zeharka dezaketen detachment failak gara daitezke, mantuaren azaleratzea ahalbidetuz. Horrekin lotuta, prozesu hidrotermalen ondorioz serpentinizatu den mantuko arrokak itsaso hondora azaleratu daitezke, edo arro sedimentarioen azpian lekutu [22] (7c. irudia). Fase hori urruneko eta kanpoko domeinuetako giltzarrien analisiaren bidez interpretatzen da. Hiperestentsioa gertatzen dela esaten da baldin lurrazal kontinentala azkeneraino luzatzen eta mehetzen bada. Horren ondorioz, subsidentzia handieneko gunea detachment faila subhorizontalaren gainean kokatzen da, eta bertara mugatzen da sedimentazio gehiena. Detachment failaren gainean, H-blokea eta horren hondarrak diren necking domeinuko bloke aloktono baskulatuak desplazatzen dira [11]. Bestalde, gertakari magmatiko eta bolkanikoak arruntak izaten dira, neurri batean behintzat, eta, gradiente geotermikoa $80^{\circ} \mathrm{C} / \mathrm{km}$ izatera hel daiteke [48]. Gainera, mantutik datozen fluidoak itsasora azaleratzen dira, uraren kimismoa $(\mathrm{pH}-\mathrm{a}$ eta mantuko ezohiko elementuen aberastasuna, besteak beste) alda daiteke, eta horrek eragina izan dezake inguruneko ekosistemetan, sedimentazioan eta diagenesian [41]. 


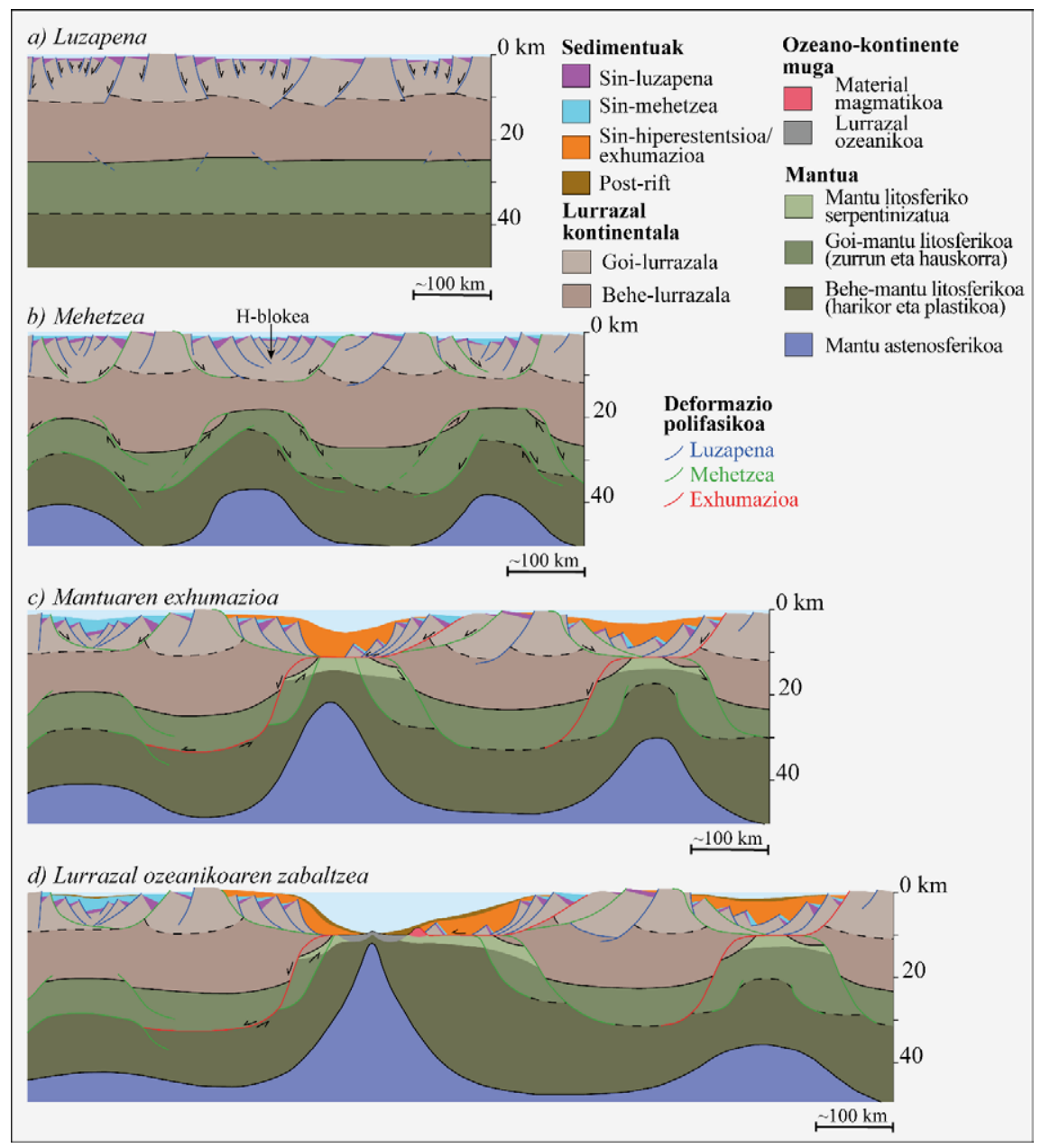

7. irudia. Deformazio polifasikoa barneratzen duen rifting-pasibo prozesuaren bilakaera eskematikoa (magman txiroak diren ertz-egonkorretarako eredua): a) Luzapena, b) Mehetzea, c) Mantuaren exhumazioa eta d) Lurrazal ozeanikoaren zabaltzea. $[7,11]$ lanetan oinarritua eta moldatua.

\subsubsection{Lurrazal ozeanikoa zabaltzea}

Mantua itsaspera exhumatu denean, prozesu termal eta mekanikoak eremu estu batean lekutzen dira, urruneko domeinuan eta ozeanikoan hain zuzen. Mantu astenosferikoaren goratzearen ondoriozko deskonpresioa eta urtzea gertatzen da. Momentu horretan, plaka litosferiko bakarra zena bitan hausten da, eta lurrazal ozeaniko berria sortzen hasten da, 
zeina ildo proto-ozeaniko baten hastapena baita. Kontinenteen apurketak bere bidea jarraitzen du, eta eremu kontinentalen ertzek subsidentzia edo hondoratze termala pairatzen dute ( $7 \mathrm{~d}$. irudia).

\section{HIPERESTENTSIOA EUSKOKANTAURIAR ARROAN}

Sarreran esan bezalaxe, Mesozoikoan irekitzen hasi zen Bizkaiko golkoaren bilakaera oso gai eztabaidatua da. Izan ere, irekitze horren ondorioz sortu zen EKA, Iberia eta Eurasia plaken mugako beste zenbait arroren antzera. Baina, aipatu bezala, irekitze horren bilakaerari buruzko proposamenak ez dira gutxi. Oro har, hiru eredu bereizten dira (8. irudia). Lehenengoa, Iberiar plakak Eurasiarekiko erlojuaren kontrako noranzkoan eginiko $35^{\circ}$ inguruko errotazioarena, «guraize irekiera» gisa deskribaturikoa [49]; bigarrena, Iberia eta Eurasia banatzen zituen urratze-faila senestro (ezker-alboranzko mugimendua duen faila) baten menpean jazotakoa [50]; eta hirugarrena, segmentuetan banaturiko hiperestentsioaren menpeko riftingari buruzkoa [20, 21]. Bereziki, gaur egun, azken ideia horren baitan ari da komunitate zientifikoa ikerketa garatzen, eta, dagoeneko, emaitza eta interpretazio solidoak eskaintzen ditu.
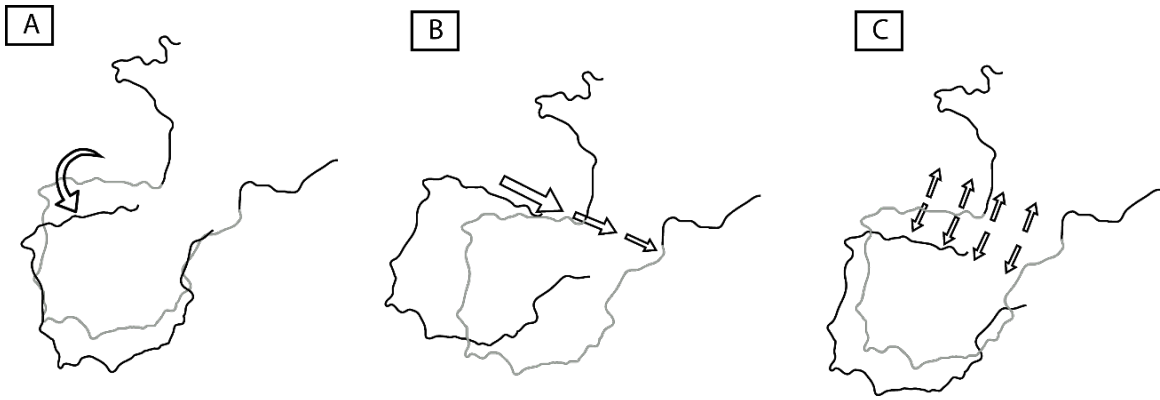

8. irudia. Iberiar plakaren eta Eurasiaren arteko erlazio zinematikoen hiru ereduak: a) guraize-irekiera, b) urratze-faila senestroaren menpekoa eta c) hiperestentsioarena. [51] lanetik hartua.

\subsection{EKAko datuak riftaren inguruan}

Orokorrean, EKAko sorrera azaltzeko Iberia eta Eurasia plaka kontinental nagusien arteko erlazio zinematikoei buruz hitz egiten da. Baina eskala txikiagoko elementuak definitzea garrantzitsua da kasu honetan. Jurasikoaren amaieran eta Kretazeoan zehar Iberia eta Eurasia plaka nagusien arteko bloke kontinental txikiagoek (adib. Ebro eta Landetako blokeak) osatzen zuten rift-sistema konplexu baten parte zen EKA [52]. Rift-sis- 
tema horrek (Pirinioak, Bizkaiko golkoa - Parentis, EKA eta Iberiar sistema) bloke eta plakak mugatzen zituen [20], plaka eta ribbon kontinentalen puzzle tektoniko bat osatuz [21, 53]. Konfigurazio tektoniko horretan rift-ertzetan identifikaturiko domeinuak ere bereizten dira (9. irudia), lurrazal kontinentalaren lodiera heterogeneoa azpimarratuz. Sistema horren parte ziren riftek bilakaera diakronikoa izan zuten, eta rift horiek ere segmentutan banatuta zeuden (Pirinioak, esaterako). Beraz, bilakaera ezberdineko hainbat rift-arro garatu ziren garai horretan, Kretazeo berantiarrean konpresioa hasi zen arte.

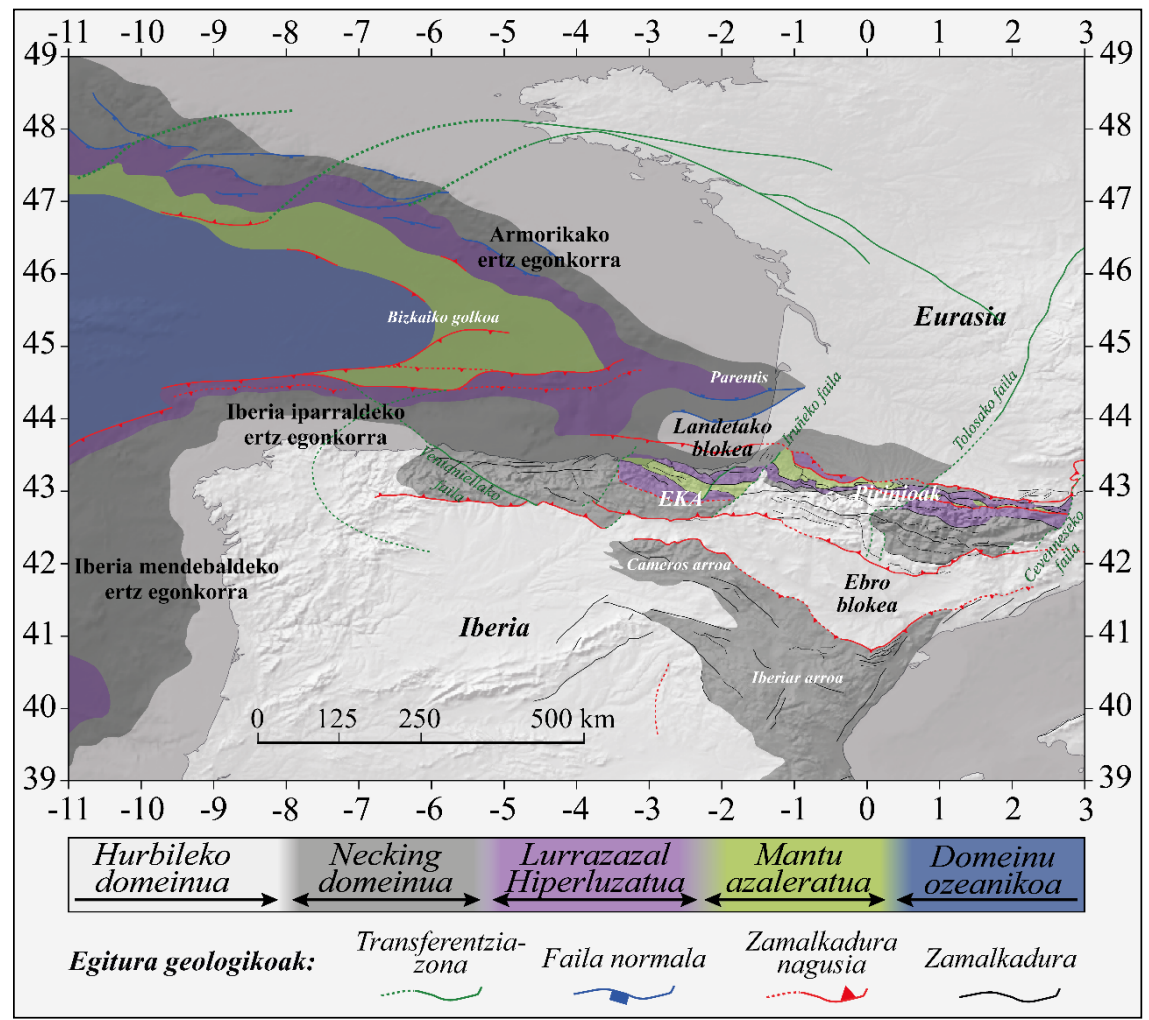

9. irudia. Hiperluzaturiko ertzetan identifikaturiko domeinuen kokapena, Bizkaiko golkoa, Parentis, EKA eta Pirinioak barneratzen dituen Mesozoiko garaiko rift-sisteman. [21] lanetik hartua eta moldatua.

Hiperestentsioaren ezaugarrietako bat mantuaren exhumazioa dela aipatu da. Pirinioetan hainbat tokitan topatu dira itsaspean birlandutako mantuko lherzolitak (arroka igneo ultramafikoak) [54]. Mantuko arroka horiek EKAko ekialdeko azaleramenduetan ere aurkitu dira, Leitzako failari lotu- 
riko Albiar-Cenomaniar garaiko tenperatura altuko metamorfismoa erakusten duen marmol-banda bati atxikirik, hain zuzen ere [22, 55]. Aipaturiko azaleramendu horietako laginen analisi petrologiko eta geokimikoek adierazten dute $\sim 200-230^{\circ} \mathrm{C}$-ko tenperatura zuten fluido gazi hidrotermalen jarduera izan zela garai hartan, gradiente geotermiko oso goratu baten seinale. Gune horretaz gain, arroan zehar ere topatu dira garaikide diren failei loturiko produktu hidrotermal eta diagenetiko gehiago ere [56-58].

Era berean, Leitza failaren hegoaldean kokatzen den Mesozoikoko sedimentuez osaturik dagoen Ultzamako azpiarroko (Nappe des Marbres [59]) unitatean eginiko ikerketetan ere topatu dira hiperestentsioarekin bat datozen deformazioren zantzuak [24]. Horretaz gain, ikerketa horretako paleo=tenperatura azterketek $550^{\circ} \mathrm{C}$-ko muga gainditu zela iradokitzen dute, eta tenperatura altuari loturiko gertakari metamorfikoak riftingaren garaikide direla interpretatzen da. Bestalde, estentsio goiztiarrari loturiko diapirismoak ere garrantzia du testuinguru geologiko horretan. Estentsioaren ondoriozko faila normalen aktibazioak Triasikoan metatutako gatz eta buztinen mobilizazioa bultzatu zuen, gatz tektonikaren bitartez antiklinalak garatuz $[24,60]$ eta sedimentazioa baldintzatuz.

Gertakari bolkanikoei dagokienez, arroan bada Albiar-Santoniar bitartean jazotako jarduera bolkanikoen erregistroa ere [60]. Itsaspean gertatutako prozesu leherkorrak [61-63], laba-koladak edota intrusio magmatikoak [64] ezagunak dira Euskal Arkuaren erdigunean [65]. Material bolkaniko horiek garai hartako itsaspeko sedimentuen artean topatzen dira, eta $2.500 \mathrm{~m}$-ko segida bolkano-sedimentarioa osatzera hel daitezke Eibar, Elgoibar, Bergara, Zumarraga eta Azkoiti udalerrien artean [66].

\subsection{Hiperestentsioa EKAn: datu zaharrak, eredu berriak}

Mantuko arroken azaleramenduek, jarduera hidrotermalak, inguruneko beroak, bolkanismoak, irudi sismikoen interpretazioak eta beste hainbat datuk EKAko estentsioa nolakoa izan zen jakitea ahalbidetzen dute [20-24]. Kretazeoko estentsioak lurrazala muturreraino luzatzea eta mehetzea ekarri zuen, detachment faila bidezko sistema konplexu baten bidez. Faila horiek mantuko arrokak azaleratzea eragin zuen zenbait tokitan, eta azaleratzetik gertu egon zen arroko beste hainbatetan [22]. Mantuak azaleratzearen ondoriozko alterazioak izan zituen (itsasoko uren infiltrazioaren ondoriozko serpentinizazioa, esaterako). Era berean, Mesozoikoko sedimentuak mantuko arroken gainean kokatu ziren, eta horiek ere fluido hidrotermalen jardueraren ondoriozko diagenesi goiztiarra (eta metamorfismoa) baldintzatu zuten askatzen zen beroarekin batera [24]. Horretaz gain, mantuaren igotzearen ondoriozko deskonpresioak magmaren sorrera bultzatu zuen. Magma horrek bilakaera estrusiboa eta fluidala zein intrusio bidezkoa izan zuen tokian-tokian, eta sedimentuen artean edota itsaspean lekutu zen. Es- 
tentsio-egoera amaitu eta konpresio alpetarra hasi zenean, hiperestentsioan garaturiko egiturak berraktibatu ziren, eta EKAren inbertsio tektonikoa baldintzatu zuten horiek.

Eredu hori garrantzitsua izan daiteke EKAren eboluzioa ulertzeko, deskribaturiko fenomeno geologiko asko bertan sartzen baitira, eta bat dator inguruko eskualde geologikoen bilakaeren zenbait interpretaziorekin ere. Azken finean, geologia ulertzeko, behar-beharrezkoa da behaketekin eta urratsez urrats eraikitako ereduetan oinarritzea, eta eredu horiek ikerlarien ulermenaren eta teknologiaren arabera moldatzen dira. Horretarako, derrigorrezkoa da geologoen arteko elkarlana modu malgu eta eraikitzaile batean bultzatzea, etor daitezkeen aldaketen aurrean eraginkorrak izaten eta datu zaharrekin eredu berriak eraikitzen laguntzeko.

\section{ESKER ONAK}

Lan honek Eusko Jaurlaritzako IT1029-16 ikertalde kontsolidatuaren, 2020.0113 UPV/EHU-TOTAL ikerketa-kontratuaren eta UPV/EHUko ikertzaileak prestatzeko PIF 19/149 bekaren babesa jaso du. Bestalde, esker onak helarazi nahi dizkiegu Fernado Sarrionandia editoreari, Arturo Apraizi eta zuzentzaile anonimoari, lan hau hobetzeko egindako zuzenketa eta aholkuengatik.

\section{BIBLIOGRAFIA}

[1] MANATSCHAL, G. 2004. «New models for evolution of magma-poor rifted margins based on a review of data and concepts from West Iberia and the Alps». Journal of Earth Science, 93, 432-466.

[2] LAVIER, L.L. eta MANATSCHAL, G. 2006. «A mechanism to thin the continental lithosphere at magma-poor margins». Nature, 440, 324-328.

[3] DORÉ, T eta LUNDIN, E. 2015. «Hyperextended continental marginsKnowns and unknowns». Geology, 43, 95-96.

[4] PÉRON-PINVIDIC, G. eta MANATSCHAL G. 2019 «Rifted Margins: State of the Art and Future Challenges». Frontiers in Earth Science, 7, 218.

[5] RESTON, T.J. 2005. «Polyphase faulting during the development of the west Galicia rifted margin». Earth and Planetary Science Letters, 237, 561-576.

[6] RANERO, C.R. eta PÉREZ-GUSSINYÉ, M. 2010. «Sequential faulting explains the asymmetry and extension discrepancy of conjugate margins». $\mathrm{Na}$ ture, 468, 294-298.

[7] PÉRON-PINVIDIC, G., MANATSCHAL, G. eta OSMUNDSEN P.T. 2013. «Structural comparison of archetypal Atlantic rifted margins: A review of observations and concepts». Marine and Petroleum Geology, 43, 21-47. 
[8] CLERC, C., RINGENBACH, J.C., JOLIVET, L., eta BALLARD, J.F. 2018. «Rifted margins: Ductile deformation, boudinage, continentward-dipping normal faults and the role of the weak lower crust». Gondwana Research, $\mathbf{5 3}, 20-40$.

[9] MANATSCHAL, G., FROITZHEIM, N. RUBENACH, M., TURRIN, B.D. 2001. «The role of detachment faulting in the formation of an ocean-continent transition: insights from the Iberia Abyssal Plain». Geological Society, Special publications, 187, 405-428.

[10] MANATSCHAL, G., SUTRA, E., eta PÉRON-PINVIDIC, G. 2010. «The lesson from the Iberia-Newfoundland rifted margins: how applicable is it to other rifted margins?». Central and North Atlantic Conjugate Margins Conference, 2, 27-37.

[11] PÉRON-PINVIDIC, G. eta MANATSCHAL, G. 2010. «From microcontinents to extensional allochtons: witnesses of how continents rift and break apart?». Petroleum Geoscience, 16, 189-197.

[12] UNTERNEHR, P., PÉRON-PINVIDIC, P., MANATSCHAL, G., eta SUTRA, E. 2010. «Hyper-extended crust in the South Atlantic: in search of a model». Petroleum Geoscience, 16, 207-215.

[13] GILLARD, M., AUTIN, J. eta MANATSCHAL, G. 2016. «Fault systems at hyper-extended crust: Structural style, evolution and relation to magma». Marine and Petroleum Geology, 76, 51-67.

[14] NIRRENGARTEN, M., KUSZNIR, N.J., SAPIN, F., DESPINOIS, F., PUBELLIER, M., CHANG, S.P., LARSEN, H.C. eta RINGENBACH, J.C. 2020. «Extension modes and breakup processes of the southeast China-Northwest Palawan conjugate rifted margins». Marine and Petroleum Geology, 113, 104-123.

[15] JAMMES, S., LAVIER, L. eta MANATSCHAL, G. 2010. «Extreme crustal thinning in the Bay of Biscay and the Western Pyrenees: From observations to modeling». Geoghemistry, Geophysics, Geosystems, 11, 10.

[16] LAGABRIELLE, Y. eta BODINIER, J.L. 2008. «Submarine reworking of exhumed subcontinental mantle rocks: field evidence from the Lherz peridotites, French Pyrenees». Terra Nova, 20, 11-21.

[17] RESTON, T. eta MANATSCHAL, G. 2011. «Rifted Margins: Building Blocks of Later Collision». BROWN, D. eta RYAN, P.D. (Edk). NON: ArcContinent Collision, Springer-Verlag Berlin, Heidelberg, 3-21.

[18] RIBES, C., MANATSCHAL, G., GHIENNE, J.F., KARNER, G.D. JOHNSON, C.A., FIGUEREDO, P.H., INCERPI, N. eta EPIN, M.E. 2019. «The syn-rift stratigraphic record across a fossil hyper-extended rifted margin: the example of the northwestern Adriatic margin exposed in the Central Alps». International Journal of Earth Sciences, 108, 2071-2095.

[19] ROBLES, S. 2014. «Euskokanauriar arroko eboluzio geologikoa». Non: BODEGO, A., MENDIA, M., ARANBURU. A., eta APRAIZ, A. (Edk). Euskokantauriar arroko geologia. Euskal Herriko Unibertsitateko Argitalpen Zerbitzua, Bilbao, 9-104. 
[20] ROCA, E., MUÑOZ, J.A., FERRER, O. eta ELLOUZ, N. 2011. «The role of the Bay of Biscay Mesozoic extensional structure in the configuration of the Pyrenean orogen: Constraints from the MARCONI deep seismic reflection survey». Tectonics, $\mathbf{3 0}, 2$.

[21] TUGEND, T., MANATSCHAL, G., KUSZNIR, N.J., MASINI, E., MOHN, G. eta THINON, I. 2014. «Formation and deformation of hyperextended rift systems: Insights from rift domain mapping in the Bay of Biscay-Pyrenees». Tectonics, 33, 1239-1276.

[22] DEFELIPE, I., PEDREIRA, D., PULGAR, J.A., IRIARTE, E. eta MENDIA, M. 2017. «Mantle exhumation and metamorphism in the Basque-Cantabrian Basin (N Spain): Stable and clumped isotope analysis in carbonates and comparison with ophicalcites in the North-Pyrenean Zone (Urdach and Lherz)». Geochemistry, Geophysics, Geosystems, 18 (2), 631-652.

[23] DEFELIPE, I., PULGAR, J.A. eta PEDREIRA, D. 2018. «Crustal structure of the eastern Basque-Cantabrian zone - western Pyrenees: from the Cretaceous hyperextension to the Cenozoic inversion». Revista de la Sociedad Geológica de España, 31 (2), 69-82.

[24] DUCOUX, M., JOLIVET, L., CALLOT, J.P., AUBOURG, C., MASINI, E., LAHFID, A. HOMONNAY, E., CAGNARD, F., GUMIAUX, C. eta BAUDIN, T. 2019. «The Nappe des Marbres Unit of the Basque-Cantabrian Basin: The Tectono-thermal Evolution of a Fossil Hyperextended Rift Basin». Tectonics, 38, 3881-3915.

[25] ALlEN, P. eta ALLEN, J.R. 2013. Basin analysis: Principles and Application to Petroleum Play Assessment (3. Edizioa). John Wiley \& Sons, Oxford.

[26] CHEN, W.P. eta MOLNAR, P. 1983. «Focal depths of intracontinental and intraplate earthquakes and their implications for the thermal and mechanical properties of the lithosphere». Journal of Geophysical Research, 88 (B5), 4183-4214.

[27] JACKSON, J. 2002. «Strength of the continental lithosphere: Time to abandon the jelly sandwich?». GSA Today, 12, 4-10.

[28] BENOIT, I., SASPITURRY, N. eta SERRANO, O. 2020. «Role of structural inheritance and salt tectonics in the formation of pseudosymmetric continental rifts on the European margin of the hyperextended Mauléon basin (Early Cretaceous Arzacq and Tartas Basins)». Marine and Petroleum Geology, 118, 104395.

[29] FRANKE, D. 2013. «Rifting, lithosphere breakup and volcanism: Comparison of magma-poor and volcanic rifted margins». Marine Petroleum Geo$\log y$, 43, 63-87.

[30] SIBUET, J.C., SRIVASTAVA, S.P. eta SPAKMAN, W. 2004. «Pyrenean orogeny and plate kinematics». Journal of Geophysical Research, 109 (B08104).

[31] GALLAHUE, M.M., STEIN, S., STEIN, C.A., JURDY, D., BARKLAGE, M. eta ROONEY, T.O. 2020. «A compilation of igneous rock volumes at volcanic passive continental margins from interpreted seismic profiles». $M a$ rine and Petroleum Geology, 122, 104635. 
[32] SCHRENBERGER, B., HINZ, K., FRANKE, D., NEBEN, S. eta ROESER, H.A. 2002. «Marine magnetic anomalies and the symmetry of the conjugated rifted margins of the South Atlantic». American Geophysical Union Fall Meeting, T52C-1217 83.

[33] WITHJACK, M.O., SCHLISCHE, R.W., OLSEN, P.E. eta ZHANG, Q. 1998. Diachronous rifting, drifting, and inversion on the passive margin of central eastern North America: an analog for other passive margins. AAPG bulletin, 82(5), 817-835.

[34] CHOROWICZ, J. 2005. The east African rift system. Journal of African Earth Sciences, 43(1-3), 379-410.

[35] SUTRA, E. eta MANATSCHAL, G. 2012. «How does the continental crust thin in a hyperextended rifted margin? Insights from the Iberia margin». Geology, 40 (2), 139-142.

[36] OSMUNDSEN, P.T eta REDFIELD, T.F. 2011. «Crustal taper and topography at passive continental margins». Terra Nova, 23, 349-361.

[37] PÉREZ-GUSSINYÉ, M., RANERO, C.R. eta RESTON. T.J. 2003. «Mechanisms of extension at nonvolcanic margins: Evidence from the Galicia interior basin, west of Iberia». Journal of Geophysical Research, 108 (B5).

[38] DE CHARPAL, O., GUENNOC, P., MONTADERT, L. eta ROBERTS, D.G. 1978. «Rifting, crustal attenuation and subsidence in the Bay of Biscay». Nature, 275 (5682), 706-711.

[39] HOFFMAN, H.J. eta RESTON, T.J. 1992. «Nature of the S reflector beneath the Galicia Banks rifted margin; preliminary results from prestack depth migration». Geology, 20 (12), 1091-1094.

[40] KRAWCZYK, C.M., RESTON, T.J., BESLIER, M.O. eta BOILLOT, G. 1996. «Evidence for detachment tectonics on the Iberia abyssal plain rifted margin». NON: Proceedings of the Ocean Drilling Program: Scientific Results, 149, 603-615.

[41] PINTO, V.H.G., MANATSCHAL, G., KARPOFF, A.M. eta VIANA, A. 2015. "Tracing mantle-reacted fluids in magma-poor rifted margins: The example of Alpine Tethyan rifted margins». Geochemistry, Geophysics, Geosystems, 16, 3271-3308.

[42] INCERPI, N., MARTIRE, L., MANATSCHAL, G. eta BERNASCONI, S.M. 2017. «Evidence of hydrothermal fluid flow in a hyperextended rifted margin: the case study of the Err nappe (SE Switzerland)». Swiss Journal of Geoscience, 110 (2), 1661-8726.

[43] INCERPI, N., MARTIRE, L., MANATSCHAL, G., BERNASCONI, S.M., GERDES, A, CZUPPON, G., PALCSU, L., KARNER, G.D., JOHNSON, C.A. eta FIGUEREDO, P.H. 2020. «Hydrothermal fluid flow associated to the extensional evolution of the Adriatic rifted margin: Insights from the pre- to post-rift sedimentary sequence (SE Switzerland, N Italy)». Basin Research, 32, 91-115.

[44] INCERPI, N., MANATCSCHAL, G., BARTIRE, L., BERNASCONI, S.M., GERDES, A. eta BERTOK, C. 2020. «Characteristics and timing of hydro- 
thermal fluid circulation in the fossil Pyrenean hyperextended rift system: new constraints from the Chaînons Béarnais (W Pyrenees)». International Journal of Earth Sciences, 109, 1071-1093.

[45] PLANKE, S,. SYMONDS, P.A., ALVESTAD, E. eta SKOGSEID, J. 2000. «Seismic volcanostratigraphy of large-volume basaltic extrusive complexes on rifted margins». Journal of Geophysical Research, 105 (B8), 1933519351.

[46] BRONNER, A., SAUTER, D., MANATSCHAL, G., PÉRON-PINVIDIC, G. eta MUNSCHY, M. 2011. «Magmatic breakup as an explanation for magmatic anomalies at magma-poor rifted margins». Nature Geoscience, 4 (8), 549-553.

[47] MOULIN, M., ASLANIAN, D., OLIVET, J.L. CONTRUCCI, I., MATIAS, L., GÉLI, L., KLINGELHOEFER, F., NOUZÉ, H., RÉHAULT, J.P. eta UNTERNEHR, P. 2005. «Geological constraints on the evolution of the Angolan margin based on reflection and refraction seismic data (ZaïAngo project)». Geophysical Journal International, 162 (3), 793-810.

[48] HART, N.R., STOCKLI, D.F., LAVIER, L.L. eta HAYMAN, N.W. 2017. «Thermal evolution of a hyperextended rift basin, Mauléon Basin, western Pyrenees». Tectonics, 36, 1103-1128.

[49] MONTADERT, L. eta WINNOCK, E. 1971. L’Histoire structurale du Golf de Gascogne. DEBYCER, J., LE PICHON, X. eta MONTADERT, L. (Edk.). NON: Histoire structurale du golfe de Gascogne. Technip, Paris.

[50] LE PICHON, X., BONNIN, J., FRANCHETEAU, J. eta SIBUET, J.C. 1971. Une hypothèse d'évolution tectonique du Golfe de Gascogne. DEBYCER, J., LE PICHON, X. eta MONTADERT, L. (Edk.). NON: Histoire structurale du golfe de Gascogne. Technip, Paris.

[51] BODEGO, A. 2019. «Bizkaiko Golkoa, Pirinioak eta plaka-tektonika». URL: https://zientziakaiera.eus/2019/06/06/bizkaiko-golkoa-pirinioak-etaplaka-tektonika/ (2019ko ekainaren 6a).

[52] NIRRENGARTEN, M., MANATSCHAL, G., TUGEND, J., KUSZNIR, N. eta SAUTER, D. 2018. «Kinematic Evolution of the Southern North Atlantic: Implications for the Formation of Hyperextended Rift Systems». Tectonics, 37, 89-118.

[53] TUGEND, J., MANATSCHAL, G. eta KUSZNIR, N.J. 2015. «Spatial and temporal evolution of hyperextended rift systems: Implication for the nature, kinematics, and timing of the Iberian-European plate boundary». Geology, 43, 15-18.

[54] LAGABRIELLE, Y. eta BODINIER, J.L. 2008. «Submarine reworking of exhumed subcontinental mantle rocks: field evidence from the Lherz peridotites, French Pyrenees». Terra Nova, 20, 11-21.

[55] ARANBURU, A., FERNÁNDEZ-MENDIOLA, P.A., LÓPEZ-HORGUE, M.A. eta GARCÍA-MONDÉJAR, J. 2002. «Syntectonic hydrothermal calcite in a faulted carbonate platform margin (Albian of Jorrios, northern Spain)». Sedimentology, 49, 875-890. 
[56] LÓPEZ-HORGUE, M.A., IRIARTE, E., SCHRÖDER, S., FERNÁNDEZMENDIOLA, P.A., CALINE, B., CORNEYLLIE, H., FRÉMONT, J., SUDRIE, M. eta ZERTI, S. 2010. «Structurally controlled hydrothermal dolomites in Albian carbonates of the Asón valley, Basque Cantabrian Basin, Northern Spain». Marine and Petroleum geology, 27, 1069-1092.

[57] BODEGO, A., ARANBURU, A., IRIARTE, E., LÓPEZ-HORGUE, M.A. eta DAMAS-MOLLÁ, L. 2018. «Primeros datos de hidrotermalismo cretácico en el margen oriental de la Cuenca Vasco-Cantábrica». Geogaceta, 64, 31-38.

[58] MENDIA, M.S. eta IBARGUCHI J.I.G. 1991. «High-grade metamorphic rocks and peridotites along the Leitza Fault (Western Pyrenees, Spain)». Geologische Rundschau, 81, 93-107.

[59] LAMARE, P. 1936. «Recherches gèologiques dans les Pyrénees basques d'Espagne». Doktorego tesia, Mém. Soc. Géol. de France, 464.

[60] BODEGO, A., IRIARTE, E., LÓPEZ-HORGUE, A. eta ÁLVAREZ, I. «Rift-margin extensional forced folds and salt tectonics in the eastern Basque-Cantabrian rift basin (western Pyrenees)». Marine and Petroleum Geology, 91, 667-682.

[61] LAMOLDA, M.A. MATHEY, B., ROSSY, M. eta SIGAL, J. 1983. «La edad del volcanismo Cretácico de Vizcaya y Gipúzcoa». Estudios Geológi$\cos , \mathbf{3 9}, 151-155$.

[62] FERNÁNDEZ-MENDIOLA, P.A. eta GARCÍA-MONDÉJAR, J. 2003. «Carbonate platform growth influenced by contemporaneous basaltic intrusion (Albian of Larrano, Spain)». Sedimentology, 50, 961-978.

[63] AGIRREZABALA, L.M., SARRIONANDIA, F. eta CARRACEDO-SÁNCHEZ, M. 2017. «Diatreme-forming volcanism in a deep-water faulted basin margin: Lower Cretaceous outcrops from the Basque-Cantabrian Basin, western Pyrenees». Journal of Volcanology and Geothermal Research, 337, 124-139.

[64] CASTAÑARES, L.M., ROBLES, S., GIMENO, D. eta BRAVO, J.C.V. 2001. «The submarine volcanic system of the Errigoiti Formation (AlbianSantonian of the Basque-Cantabrian Basin, Northern Spain): stratigraphic framework, facies, and sequences». Journal of Sedimentary Research, $\mathbf{7 1}$ (2), 318-333.

[65] RAT, P. 1959. «Les pays crétacés basco-cantabriques (Espagne)». Doktorego tesia, Université de Dijon, Dijon, 525 or.

[66] CARRACEDO-SÁNCHEZ, M., SARRIONANDIA, F. eta JUTEAU, T. 2012. «El Vulcanismo Submarino de Edad Cretácica de la Cuenca VascoCantábrica». Revista de la Sociedad Española de Mineralogía, 16, 260-267. 
